\title{
Method of Supplier Selection by Means of Correlation of Quality and Cost Characteristics of Products
}

\author{
DOI: 10.12776/QIP.V22I3.1189
}

\author{
Mikhail Gennady Shalygin
}

Received: 22 October 2018 Accepted: 24 November 2018 Published: 30 November 2018

\begin{abstract}
Purpose: When choosing a supplier, many companies give priority to the lowest cost of products. Problems arise when the consumer wants to buy products with several better quality characteristics, but the products have only one of them. The aim is to establish a link between the quality characteristics of the product and its market value in terms of consumer benefits.
\end{abstract}

Methodology/Approach: The proposed model is based on determining the importance of criteria that determine the indicators of quality, reliability, characteristics of products and their comparison with the market price at which these products are supplied to the consumer. The model is built on the basis of statistical processing of the data received from consumers about preferences at the choice of production.

Findings: The method of determining the optimal supplier based on the cost and quality indicators of the product. Some indicators of the quality of products and their ranking by significance for the consumer are given. It gives the examples of calculation methods for univariate and two-factor analysis. It shows the ways of diagramming the determination of values of factors of production.

Research Limitation/implication: The model is relevant only at close market value of production for the consumer.

Originality/Value of paper: The methodology of criteria-based evaluation of the quality indicators of the supplied products or services allows making a selection of a products supplier on the basis of quality characteristics of the supplied products.

Category: Research paper

Keywords: supplier selection; the quality of the products; the reliability of the supplier; multivariate analysis 


\section{INTRODUCTION}

In today's world, contracts for the supply of components, products or services, are concluded at the end of the auction. According to the rules of auctions, the person who has offered the best contract from the financial point of view, taking into account the requirements of the customer, is declared the winner. Thus, the only criterion for selection of the contractor under the contract is the contract sum proposed by the contractor. A lot of companies conclude contracts with suppliers directly, without auctions. In this case selection criteria of the contractor are the amount of the contract and the quality of work or of the supplied equipment, components etc. If the amount priority of the contract is clear, than the quality characteristics are mapped according to the principle: those, whose values are above, are preferred. It often happens that the procurement services of companies are faced with a situation when different suppliers have opposite values of the indicators of interest of products and inversely proportional values of the contract amount or when it is required to choose the products on several quality parameters which don't state the obvious leader. This choice affects the economic, logistic and production characteristics of the finished product of the customer (Shalygin, 2012). In such cases, various existing techniques are used, including estimations (Sysolyatin, 2014), analyze the variables that impact quality in a manufacturing environment (Omachonu, Suthummanon and Einspruch, 2004). The approach closest to the proposed methodology is proposed by Visawan and Tannock (2004) is based on costs and benefits Hajduova (2014) based on an estimate of the cost of improving processes.

One of the ways to improve the competitiveness of the enterprise in procurement is the paradigm of "flexibility" described in the works by Goldman and Nagel (1993) and Goldman, Nagel and Preiss (1995) which is characterized by the ability to respond to frequent and unpredictable changes. Many existing prioritysetting methods have limited application, as they consider only independent evaluation criteria as defined in article Gallouj and Weinstein (1997). Saaty (1996) it is proposed to use the analytical hierarchy process to establish the relationship between criteria and alternatives, which can be used as the cost of production. Lin and Hsu (2008) when independence among different elements of a system assumption is violated and takes into account the degree of the interdependence among them. In this paper, we consider the innovations that are characteristic of wholesale trade in terms of the interdependence between the factors that take into account the qualitative aspects of flexibility. Agovino at al. (2017) presents the methodology for constructing the index of efficiency of firms, taking into account both the quantity and quality of research. However, this paper does not take into account the cost of the final product obtained from scientific research.

The article by Sánchez Vijande and Gutiérrez (2012) examines the impact of value creation functions on satisfaction and loyalty in business markets. Based on the study, the authors point out that the satisfaction of the distributor largely 
depends on the indirect value creation functions performed by the manufacturer. Distributors loyalty is directly affected by indirect value creation functions, but there is no evidence that benefit, volume and protection functions do this.

Effective resource management is critical in terms of duration, cost and quality of the product to the consumer. In work Tran et al. (2018), researchers have developed several models to help planners in developing practical and nearoptimal schedules for repetitive projects. Despite their undeniable advantages, such models do not have the possibility of pure simultaneous optimization, as existing methodologies optimize the schedule in relation to one factor to achieve the minimum duration, total cost, resource interruptions or different combinations, respectively.

In the paper by He, Chan and Tse (2008) examines the relationships between consumer satisfaction, price tolerance and repurchase intention. The estimation of consumers' tolerance to growth/decrease in prices is made. Results show that satisfied consumers may not necessarily be willing to accept an increased price for competitive services while less satisfied consumers certainly demand some price discounts. It is shown that since the maintenance of satisfied consumers by improving the quality of services is cheaper for firms than attracting less satisfied ones by reducing prices, efforts to satisfy consumers are paid off by increasing consumer loyalty and, consequently, the profitability of firms, but the quality characteristics of products that satisfy the consumer are not considered.

The most closely considered situation is described in the article by Ebrahimipour Shoja and $\mathrm{Li}$ (2016). The proposed model is based on the product life cycle and its impact on the choice of the supplier, the structure of the product, competitive supply environment and various criteria for assessing the quality of the product. As an illustration of the model, scenarios describing the structure of the product, uncertainty in purchase prices, reliability of purchased components, machine downtime due to poor quality of components, power of suppliers and delivery times are presented. However, the proposed model does not take into account the final cost of production and the ratio of cost and quality of the product for the end user.

The purpose of this article is to offer methodology and criteria-based evaluation of the quality indicators of the supplied products or services subject to price delivery.

\section{METHODOLOGY}

The article offers to do assessments by comparing criteria assessment of proposals of suppliers costs.

$$
\Phi=k_{1} X_{1}+k_{2} X_{2}+\cdots+k_{n} X_{n}
$$


where $\Phi$ - is the criterion of proposal of suppliers, taking into account the amount of the contract; $k$ - is the weighting factor; $X$ - is the considered quality factor of the products; $n$ - is the number of the considered factors.

Suppose, we consider a potential supplier with the contract amount $P$. The supplier's products correspond to the factors of interest to consumers $F_{1}, F_{2} \ldots F_{n}$. The supplier's reliability is estimated by the expression:

$$
H=\frac{N-N_{f}}{N+1}
$$

where $N$ - is the number of the contracts, concluded by the contractor earlier with the potential supplier; $N_{f}$ - is the number of the contracts which were executed by the supplier efficiently, in time, in full compliance with the contractor's requirements.

The supplier's reliability indicator may vary within [0;1], and for a reliable supplier the indicator $H \rightarrow 0$. For a new supplier, unknown to the customer, the value of the reliability indicator should be $H=0.5$.

To determine each quality factor of the products it is necessary to graph the function:

$$
f(x)=\frac{F_{i}}{x \cdot F_{\text {st } i}}
$$

where $F_{i}$ - is the quality factor of the products of interest to the customer; $F_{s t i}$ is the minimum value of the factor, determined by the contractor, based on the contractor's requirements, standard and so on; $x \in[0.1 ; 1]$.

A separate function is built for each factor and marked in the diagram. The contract amount $P$, proposed by the potential supplier, the highest price which the contractor is willing to pay under the contract $C_{\max }$; the minimum price which the customer believes is reasonable $C_{\min }$; the average price in the market for similar products $C_{m i d}$ are marked in the diagram on the axis $\mathrm{OY}_{2}$.

The value of $X_{n}$ is calculated for each factor as the abscissa of the point of intersection of the graph of the function $f_{n}(x)$ and the value of the contract amount $P$, proposed by the customer. If the point of intersection is above the line of the maximum allowable price $C_{\max }$ or below the line of the minimum allowable price $C_{\min }$, than the value of this factor should be considered high or low, respectively.

The expression (1) is used to calculate criteria $\Phi$ for each of the considered suppliers. The weight factors $k$ are determined based on the importance of each individual criterion with the coefficient for the customer, given the conditions, that $k_{1}+k_{2}+\cdots+k_{n}=1$. 
Suppose, we consider the potential suppliers 1 and 2. The amounts proposed for the contract by the suppliers $P_{1}$ and $P_{2}$, respectively, and $P_{1}>P_{2}$. The highest and the minimum prices which the customer is willing to pay for the contract are respectively $C_{\max }$ and $C_{\text {min }}$. It is important for the customer that the values of the quality factor $F$ are the more the better. The values of $F$ factors for each potential supplier are $F_{1}$ and $F_{2}$, and $F_{1}<F_{2}$.

The customer concluded contracts with each of the potential suppliers, than expression (2) is used to determine the reliability of each of the potential customers $H_{1}$ and $H_{2}$. Taking into account that only one quality factor is considered, it is possible to mark two suppliers in one graph (Fig. 1).

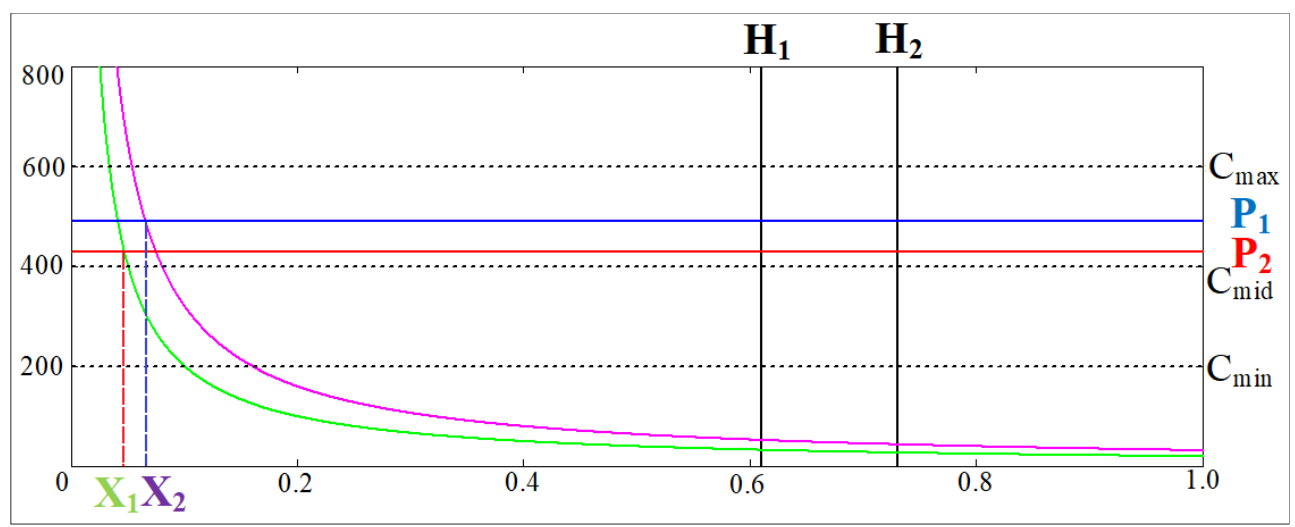

Figure 1 - Diagram of the Evaluation of Factor Values

Using the diagram we determine the values of the quality factors in the studied criterion for each potential supplier $X_{1}$ and $X_{2}$. Given that only one factor is considered, the value of the weighting factor is taken as one for each supplier $k_{1}=1$. Than it is obvious that the value of criterion $\Phi_{2}$ is more than the value of criterion $\Phi_{1}$. Thus, supplier 2 should be preferred when concluding a contract.

In case of equal values of the quality factors $X_{1}$ and $X_{2}$, for univariate analysis, a choice should be made taking into consideration reliability of the supplier, in that case expression (1) takes the form:

$$
\Phi=k_{1} \frac{X_{1}}{H}+k_{2} \frac{X_{2}}{H}+\cdots+k_{n} \frac{X_{n}}{H}
$$

\section{RESULTS}

Suppose that you want to buy a cell phone. The highest price which the customer is willing to pay is $C_{\max }=1050 \$$, the minimum price is $C_{\min }=950 \$$. The average price on the market is assumed equal to the average value between minimum and maximum prices $C_{\text {mid }}=1000 \$$. As factors, important for the 
supplier, we choose the battery capacity (operation time without recharging) $F_{1}$ and storage capacity $F_{2}$. In this case, preference is given to large values of these factors.

In a suitable price range and closer to the value $C_{\text {mid }}$, there are the smartphones of the companies $A$ and $S$. The price of the smartphone of company $A$ on the market is $P^{A}=1015 \$$, the price of the smartphone of company $S$ is equal to $P^{S}=999 \$$. As the products of these suppliers have never been purchased before we take for them equal reliability indexes $H_{1}=H_{2}=0.5$. For supplier $A$ the values of the factors are $F_{1}=1960 \mathrm{mAh}, F_{2}=256 \mathrm{GiB}$, for the supplier the values of the factors $-F_{1}=3500 \mathrm{mAh}, F_{2}=64 \mathrm{GiB}$. Using the expression 3 let's build graphs of functions for each of the criteria $F$ (Fig. 2) and $F_{2}$ (Fig. 3).

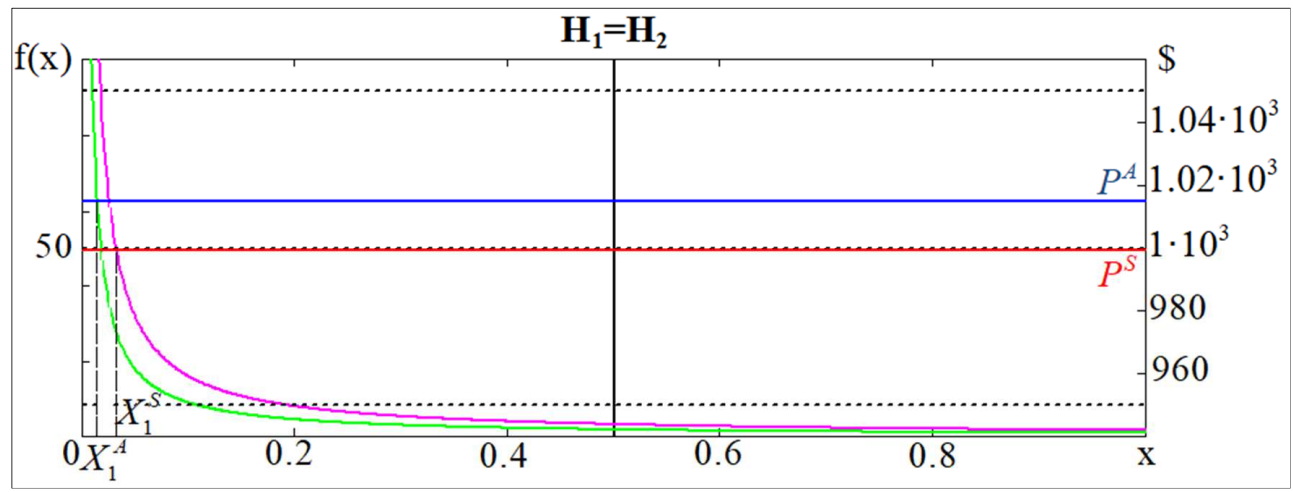

Figure 2 - Diagram of Rating Factor F1 Value

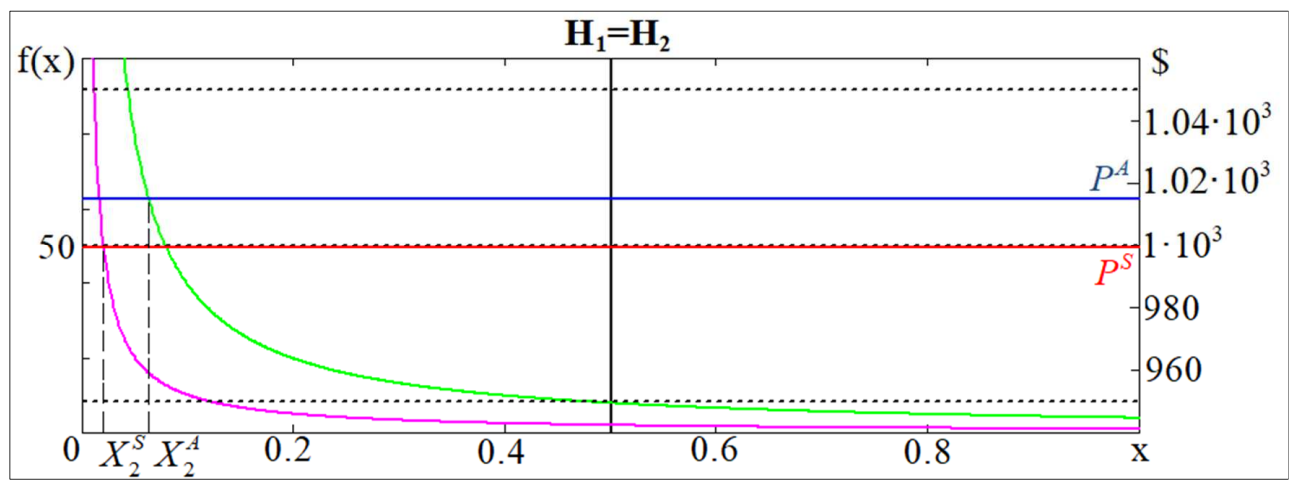

Figure 3 - Diagram of Rating Factor F2 Value

The minimum requirements for the factors are adopted, the smartphone must have the battery capacity more than $F_{s t 1}=2200 \mathrm{mAh}$ and storage capacity more than $F_{\text {st } 2}=65 \mathrm{GiB}$. All the calculations are summarized in Tab. 1 . 
Table 1 - Values of Factors and Parameters

\begin{tabular}{|c|c|c|}
\hline Designation & Company $A$ & Company $S$ \\
\hline$P$ & 1015 & 999 \\
\hline$H$ & 0.5 & 0.5 \\
\hline$F_{1}$ & 1960 & 3500 \\
\hline$F_{2}$ & 256 & 65 \\
\hline$C_{\max }$ & \multicolumn{2}{|c|}{1050} \\
\hline$C_{\min }$ & \multicolumn{2}{|c|}{950} \\
\hline$C_{\text {mid }}$ & \multicolumn{2}{|c|}{1000} \\
\hline$F_{s t 1}$ & \multicolumn{2}{|c|}{2200} \\
\hline$F_{s t 2}$ & \multicolumn{2}{|c|}{65} \\
\hline$k_{1}=k_{2}$ & \multicolumn{2}{|c|}{0.5} \\
\hline$f_{1}(x)$ & \multirow{2}{*}{$\frac{F_{1}}{x \cdot F_{s t}}$} & \multirow{2}{*}{$\frac{F_{2}}{x \cdot F_{s t 2}}$} \\
\hline$f_{2}(x)$ & & \\
\hline$X_{1}$ & 0.014 & 0.033 \\
\hline$X_{2}$ & 0.062 & 0.021 \\
\hline$\Phi$ & 0.038 & 0.027 \\
\hline
\end{tabular}

Thus, the values of the factors for company $A$ are equal to $X_{1}^{A}=0.014$, $X_{2}^{A}=0.062$, for company $S$ they are equal to $X_{1}^{S}=0.033, X_{2}^{S}=0.021$. As each of the factors is equally important for the customer, the weighting factors are assumed to be equal $k_{1}=k_{2}=0.5$, than using expression (1) we define the offer criteria of the companies $\Phi^{A}=0.038, \Phi^{S}=0.027$, hence we see that $\Phi^{A}>\Phi^{S}$. So, the products of company $A$ should be preferred.

\section{CONCLUSION}

This document provides a methodology for selecting a supplier of products or services. Under this methodology introduces a weight quantity of the product characteristics on which the plot of the values of the factors. When comparing the value of factors, the choice is made in favour of a product or service.

The methodology of criteria-based evaluation of the quality indicators of the supplied products or services allows making a selection of a products supplier on the basis of quantity characteristics of the supplied products. The methodology is based on comparing the characteristics of the product or service with the price of the product. The value of all the variables present in the methodology can be obtained from the supplier. 
The methodology allows you to choose a supplier not only based on product prices and quantitative factors, but also to assess the importance of these factors for the end user based on his needs.

\section{REFERENCES}

Agovino, M., Aldieri, L., Garofalo, A. and Vinci, C.P., 2017. Quality and quantity in the innovation process of firms: a statistical approach. Quality \& Quantity, 51(4), pp. 1579-1591. doi.org/10.1007/s11135-016-0353-y.

Ebrahimipour, V., Shoja, B.M. and Li, S., 2016. Supplier selection considering product structure and product life cycle cost. International Journal of Quality \& Reliability Management, 33(5), pp. 654-675. doi.org/10.1108/IJQRM-05-20150069.

Gallouj, F. and Weinstein, O., 1997. Innovation in services. Research Policy, 26(4-5), pp. 537-556.

Goldman, S.L. and Nagel, R.N., 1993. Management, technology, and agility: the emergence of a new era in manufacturing. International Journal of Technology Management, 8(1-2), pp. 18-38.

Goldman, S.L., Nagel, R.N. and Preiss, K., 1995. Agile Competitors and Virtual Organizations: Strategies for Enriching the Customer. New York: Van Nostrand Reinhold.

Hajduova, Z., 2014. Integrated cost model for improving the production in companies. Quality Innovation Prosperity, 18(2), pp. 90-99. doi.org/10.12776/QIP.V18I2.379.

He, Y., Chan, L.K. and Tse, S.-K., 2008. From consumer satisfaction to repurchase intention: The role of price tolerance in a competitive service market. Total Quality Management \& Business Excellence, 19(9), pp. 949-961. doi.org/10.1080/14783360802224628.

Lin, L.-Z. and Hsu, T.-H., 2008. The Qualitative and Quantitative Models for Performance Measurement Systems: The Agile Service Development. Quality \& Quantity, 42(227), pp. 445-476. doi.org/10.1007/s11135-006-9053-3.

Omachonu, V.K., Suthummanon, S. and Einspruch, N.G., 2004. The relationship between quality and quality cost for a manufacturing company. International Journal of Quality \& Reliability Management, 21(3), pp.277-290.

Saaty, T.L., 1996. The Analytic Network Process. Pittsburgh: RWS Publications.

Sánchez, J.A.L., Vijande, M.L.S. and Gutiérrez, J.A.T., 2012. Value-creating functions, satisfaction and loyalty in business markets: a categorical variable approach using a robust methodology under structural equation modeling. Quality \& Quantity, 46(3), pp. 777-794. doi.org/10.1007/s11135-010-9413-x. 
Shalygin, M.G., 2012. The state and prospects of development of machinebuilding complex of the Bryansk region. Construction and road machines, 1, pp. 50-52.

Sysolyatin, A.V., 2014. The choice of the supplier in the procurement activities of trading companies. Nauka-rastudent.ru, [e-journal] 12, pp. 24-38. Available at: <http://nauka-rastudent.ru/12/2256/> [Accessed 13 August 2018].

Tran, D.-H., Luong-Duc, L., Duong, M.-T., Le, T.-H. and Pham, A.-D., 2018. Opposition multiple objective symbiotic organisms search (OMOSOS) for time, cost, quality and work continuity tradeoff in repetitive projects. Journal of Computational Design and Engineering, 5(2), pp. 160-172. doi.org/10.1016/j.jcde.2017.11.008.

Visawan, D. and Tannock, J., 2004. Simulation of the economics of quality improvement in manufacturing: A case study from the Thai automotive industry. International Journal of Quality \& Reliability Management, 21(6), pp.638-654. https://doi.org/10.1108/02656710410542043.

\section{ABOUT THE AUTHOR}

Mikhail Gennady Shalygin - doctor of technical Sciences, was born in 1983. Professor of the department "Quality Management, Standardization and Metrology", senior researcher of the research laboratory "Engineering of Materials and Adaptive Technological Systems" of Bryansk State Technical University, Bryansk, Russia. Author of more than 60 publications in the field of surface quality and quality management systems. E-mail: migshalygin@yandex.ru, Author's ORCID: https://orcid.org/0000-0002-81029918.

(C) 2018 by the authors. Submitted for possible open access publication under the terms and conditions of the Creative Commons Attribution (CC-BY) license (http://creativecommons.org/licenses/by/4.0/). 